\title{
Professional attitudes to psychiatric patients: a time for change and an end to medical paternalism
}

\author{
NICHOLAS TARRIER and CHRISTINE BARROWCLOUGH
}

\begin{abstract}
Abuse of patients by professional staff has made headline news over the past few years on a number of occasions. Undoubtedly the most extreme and shocking example was the case of the mass murderer, Dr Harold Shipman. In January 2000 Dr Shipman, a general practitioner from Ashton, a town on the edge of Manchester, was convicted and sentenced to life imprisonment, for the murder of 15 of his patients. He is suspected of murdering between 200 to 400 more people under his care, making him the biggest known serial killer in England in modern times. Most of his victims were elderly and the murders were apparently without motive; there was no indication that these crimes were carried out principally for personal gain. We would all prefer to assume that the Shipman case resulted from the actions of a singularly disturbed and psychopathic personality and is unlikely ever to be repeated. This may well be true, but can the Shipman case tell us something about the potential for abuse inherent in the imbalance of power in health care provider-user relationships?
\end{abstract}

Less extreme but very disturbing examples of grossly inhumane practices in health care staff are not hard to find. On $5^{\text {th }}$ December 2002, the BBC ran a story on national television about the suspension of a number of psychiatric nurses after allegations of physical and emotional abuse of patients on a psycho-geriatric ward in Manchester. Allegedly this abuse had been going on for a number of

Address for correspondence: Professor N. Tarrier, Academic Division of Clinical Psychology, School of Psychiatry and Behavioral Science, University of Manchester, Wythenshawe Hospital, Manchester M23 9LT (UK).

Fax: +44-161-291.5882

E-mail: nicholas.tarrier@man.ac.uk years. On $9^{\text {th }}$ March 2003, The Independent on Sunday newspaper printed a story on abuse towards women patients at Broadmoor Special Hospital. The article reported that "From sexual abuse to rape, the abusive treatment of women patients at Broadmoor has been exposed in horrifying detail...". The story was sub-titled "Macho culture blamed for plight of female patients"., with the implication that women patients were not safe and lacked protection, being treated as "second class citizens" and "subjected to bullying by other patients if they complained about sexual abuse". The article strongly suggested that the very high rates of self harm were regarded as "the women playing up again" and those who reported abuse or bullying being "labelled as liars".

We suspect that most countries will have their own examples of professional staff abusing patients. Although most will not result in physical or sexual abuse, let alone mass murder, the uncomfortable question remains as to whether these are isolated cases perpetrated by disturbed or criminal individuals. An alternative viewpoint is that there is a continuum of attitudes from health care staff towards service users. In this context, the headline cases represent the worst scenarios of what can happen in insulated institutional settings when extreme negative attitudes towards a vulnerable and powerless group of patients prevail. Furthermore, the uncomfortable question we need to address is whether negative attitudes are somehow fostered, albeit unwittingly, by aspects of professional training? Attitudes and beliefs held by health and social care staff and the safeguards of clinical governance are important because they determine how professionals behave towards their patients and mental health service users, some of whom will be vulnerable and disadvantaged. In mental health, such attitudes and behaviours may be seen on a continuum from the highest standards of respect and joint patient - provider collaborative working, 
with a middle ground of benevolent paternalism where the provider is assumed to know best without the safeguards of clinical governance including regard for evidencebased interventions and the careful reflection on practice. The unpalatable negative end of such a continuum may be patient abuse. The middle ground of poor practice can result from negligence or disinterest because the recipient is perceived as unimportant or without power, or because professional training or mores have fostered the belief that the practitioner is right irrespective of the evidence.

How could it be that professionals entrusted with the care of the vulnerable could develop such negative attitudes towards patients? Kafka's book Metamorphosis is a literary example of how a person can lose their identity and become powerless, helpless and stigmatised as a result of disability, inviting a change in attitude and behaviour from others in their social group. The stigmatising effect of mental illness is well known, and in recent years often strongly reinforced by the powerful effects of the media. For example, after an extensive media campaign SANE-Australia forced Sony to withdraw offensive promotional material of a Play-Station game in which characters "explicitly labelled as mentally ill in promotional materials, exhibited bizarre features and violent tendencies" (WFSAD Newsletter, 2002). If those who are most vulnerable to psychiatric disorders come from lower social groups while those responsible for their care come from more powerful social groups then the disparity in power and influence combined with the dehumanising loss of identity associated with mental illness may lay the ground for neglect and even ill-treatment. The problem is that the extreme examples of ill-treatment and criminal behaviour, although abhorrent in themselves, may divert attention from much more common place attitudes and behaviour that can detrimentally affect those suffering from mental disorders. It would be all too easy to adopt the attitude that "this does not affect me because I would never do such terrible things". But is it true that this issue does not affect all of us who work in mental health or health care as a whole? We would suggest that inequality in the clinician-patient relationship and attitudes and behaviour of professional staff are topics that affect us all and have a potentially enormous impact on those who receive our services. To focus only on cases of extreme and criminal abuse is to miss the point. Inequalities in mental health care dependent on socio-economic and ethnic origins are well documented. For example, Lorant et al. (2003) recently report on the likelihood of favourable setting and nature of treatment (eg psychotherapy) occurring with increase in socio-economic status in inpatient psychiatric care in Belgium.
Experimental studies from social psychology, for example the well known studies on authority and conformity performed by Milgram (1974) and the Stamford Prison Experiment of Zimbado et al. (Haney et al., 1973; Zimbardo et al., 2000), have provided potent demonstrations that perfectly ordinary people can behave in a cruel and authoritarian way to others when social rank and context are manipulated. Thus it is likely that difference in social rank, prevalent attitudes and stigmatisation of those suffering mental illness or disorder may, under certain conditions, reduce the probability of cooperative and caring behaviour. Certain aspects of medical practice may inadvertently contribute to these processes. For example, an over-emphasis on biological aspects of psychiatry may minimise and devalue social and psychological factors contributing to the person's difficulties, thus providing the rationale and justification for paternalistic behaviour and attitudes from medical staff. Linsley et al. (2001) have recently commented that psychological treatments in psychosis entail an ability to work closely with patients in a way that may be novel and difficult for trainee psychiatrists who have been exposed to a more paternalistic medical approach. More obviously, too close a relationship with drug companies and their commercial activities also gives potential for conflict of interest and possible devaluing of patient's interests. Clinicians often receive direct or indirect payment for recruiting their patients into drug studies, but this effectively treats the patient as a purchasable commodity.

Beliefs held by professional staff, in general, but also specifically about individual patients can have a subtle effect on their treatment. A few examples will suffice to demonstrate that common everyday attitudes of professional staff can have real or potentially negative consequences for the patient. There is now considerable research on the effect of interpersonal environments on psychiatric and psychological disorders. Specifically, the research on Expressed Emotion (EE) has demonstrated that negative aspects of the social and interpersonal environment can have a detrimental effect on the course of such disorders. Much of this research has been carried out in schizophrenia, where it has been consistently demonstrated that living with critical, hostile or over-involved informal carers (family members) is associated with higher rates of subsequent relapse (Butzlaff \& Hooley, 1998). But this effect is not unique to schizophrenia and has also been demonstrated in depression and anxiety disorders (Wearden et al., 2000). It seems probable that EE responses are a combination of cognitive and affective reactions driven by beliefs about the patient's behaviour and illness. But high EE should not be seen as a pejorative la- 
bel, as this response can be viewed as almost more normal in a group of informal carers attempting to do their best to reconstitute normality in difficult circumstances. However, the high EE response appears to result in behaviour detrimental to the patient's welfare because it is based on specific beliefs and attitudes. Believing that the patient has the potential to have more control over their symptoms and problems than they are willing to exert is likely to result in criticism and hostility and attempts to coerce the patient to behave differently (Barrowclough et al., 1994; Tarrier et al., 2002). Even when motivated by what others see as the patient's best interests, these strategies are likely to have a detrimental effect on patients and lead to a sense of frustration and less willingness to help on the part of the care provider.

Thus there is strong evidence that patients suffering from psychiatric and psychological disorders are significantly affected by social interactions with those in their environment. That this also includes professional staff is evidenced by accumulating evidence that staff $E E$ also in fluences outcome in schizophrenic patients (Kuipers, 1998). In a recent prospective study, Tattan \& Tarrier (2000) used a controlled trial of the effectiveness of different intensities of case management as an opportunity to assess the quality of the relationship between case managers and patients suffering from serious mental illness on later clinical outcomes. EE was assessed 3 months after the case managers became responsible for the patients care and the patients' clinical outcome was assessed independently and blind to the EE status of the case managers at a 12 months follow up point. High EE ratings were significantly associated with individual case managers and not to symptoms or illness factors. The absence of a positive relationship between case manager and patient measured after 3 months was significantly associated with poorer clinical outcome 9 months later. In a similar investigation of staff attitudes on a low security inpatient unit no examples of high $\mathrm{EE}$ were found. But analysing the beliefs or causal attributions held by staff demonstrated that staff held negative attitudes towards patients whose problem behaviour they perceived to be controllable, that is dependent on the patient's own volition. The more negatively perceived patients were more likely to have behavioural disturbances in the subsequent seven months, raising the question as to whether patients are more likely to be disturbed on environments where staff hold negative attitudes to them, especially as the results of this study demonstrated that patients were sensitive to staff attitudes towards them (Barrowclough et al., 2001).

In another study investigating staff attitudes to distressed patients, 89 medical and nursing staff from
Accident \& Emergency Departments were asked to rate hypothetical vignettes about a patient presenting with deliberate self-harm (Makay, 2002). The findings were consistent with an attributional model of helping (Weiner, 1980). The greater the control the patient was perceived to have over the events, the greater the negative affect of staff towards the person, and the less propensity to help. The greater stability perceived in the patient's behaviour then the lower staff optimism that they could change the patient's behaviour and the less propensity to help (Makay \& Barrowclough, submitted for publication). Furthermore, although medical staff, especially males, expressed greater irritation, less personal optimism and less willingness to help they perceived their need for further training as significantly less than their nursing colleagues. Other research has reported that medical personnel are perceived to provide the most unsatisfactory support by self-harming patients (Warm et al., 2002).

The vast majority of health care professionals are committed, hard working and caring people who intend to behave in an ethical manner with the best interests of their patients in mind. However, circumstances can conspire to sabotage this intent. Professional staff must be aware that their attitudes, beliefs and behaviour can have a profound effect on those that they treat, not always in the way they intend. Without an equality and collaboration between those who provide and those who use professional mental health service there is always a risk of paternalism, stigmatisation and coercion. Hospitalisation, especially involuntarily can have a profoundly traumatic effect on psychotic patients, so much so that it has been claimed that post-traumatic stress disorder can be a common result (Morrison et al., 1999; Frame \& Morrison, 2001). In spite of this, the potential for such morbidity is rarely recognised or considered in planning either clinical decisions or mental health services. Many users of mental health services would claim that the very treatments and services supposedly designed to help them actually have an iatrogenic effect, however, their voice is rarely heard. Mental health services should be democratised and service users involved at all levels in their planning and management (see Department of Health, 2003). But there is probably more to be done than just righteous indignation and a call for vigilance and reflection. Experimental models and methodologies from social psychology have helped us understand the underlying beliefs that determine interpersonal behaviour in the informal carers of those suffering from psychological and psychiatric disorders (Wearden et al., 2000; Barrowclough \& Hooley (in press). The same methods could aid understanding of how attributions and beliefs about causality held by professional staff deter- 
mine their behaviour, for good or ill. Professional training should, both through selection and intervention, aim to change beliefs and behaviours towards one of equal collaboration and away from paternalism and self-interest. The recognition that the laws that govern human behaviour in general also govern our own behaviour whilst we act in our professional capacity, and that our own behaviour as professional can and should be open to scrutiny, investigation and modification would be a good start.

\section{REFERENCES}

Barrowclough C. \& Hooley, J.M. (in press). Attributions and expressed emotion: a review. Clinical Psychology Review.

Barrowclough C., Johnston C. \& Tarrier N. (1994). Attribution, expressed emotion and patient relapse: an attributional model of relatives' response to schizophrenic illness. Behaviour Therapy 25, 67-88.

Barrowclough C., Haddock G., Lowens I., Connor A., Pidliswyj J. \& Tracey N. (2001). Staff Expressed Emotion and causal attributions for client problems on a low security unit: an exploratory study. Schizophrenia Bulletin 27, 517-526.

Butzlaff R.L. \& Hooley J.M. (1998). Expressed emotion and psychiatric relapse: a meta-analysis. Archives of General Psychiatry 35, 547-552.

Department of Health (2003). NHS Research and Development Strategic Review of Mental Health. Appendix 5, Report of the Service Users Panel. Department of Health: London.

Frame L. \& Morrison A.P. (2001). Causes of posttraumatic stress in psychotic patients. Archives of General Psychiatry 58, 305-306.

Haney C., Banks W.C. \& Zimbardo P.G. (1973). Interpersonal dynamics in a simulated prison. International Joumal of Criminology and Penology 1, 69-97.

Kuipers E. (1998). Working with carers: interventions for relative and staff carers of those who have a psychosis. In Outcome and Innovation in Psychological Treatment of Schizophrenia. Wiley: Chichester.
Linsley K., Slinn R., Nathan R., Guest L. \& Griffiths H. (2001). Training implications of community oriented psychiatry. Advances in Psychiatric Treatment 7, 208-215.

Lorant V., Kamgfl D., Seghers A., Delege D., Closen M-C. \& Ansseau M. (2003). Socio-economic differences psychiatric in-patient care. Acta Psychiatrica Scandinavica 107, 170-177.

Makay N. (2002). Accident and emergency staffs ${ }^{*}$ responses towards deliberate self-harm: the influence of causal attributions on emotional responses, optimism and helping behaviour. Doctor of Clinical Psychology thesis, Faculty of Medicine, University of Manchester.

Makay N. \& Barrowclough C. (submitted for publication). Accident and Emergency staff's perceptions of deliberate self harm: emotions and willingness to help.

Milgram S. (1974). Obedience to Authority: an Experimental View. Harper \& Row: New York.

Morrison A.P., Bowe S., Larkin W. \& Nothard S. (1999). The psychological impact of psychiatric admission: some preliminary findings. Journal of Nervous \& Mental Disease 187, 250-253.

Tarrier N., Barrowclough C., Ward J., Donaldson C. \& Burns A (2002). Expressed emotion and attributions in the carers of patients with Alzheimer's disease: the effect on carer burden. Journal of Abnormal Psychology 111, 340-349.

Tattan T. \& Tarrier N. (2000). The Expressed Emotion of case managers of the seriously mentally ill: the influence of EE and the quality of the relationship on clinical outcomes. Psychological Medicine 30. 195-204.

Warm A., Murray C. \& Fox J. (2002). Who helps? Supporting people who self harm. Journal of Mental Health 11, 121-130.

Wearden A., Tarrier N., Barrowclough C., Zastowny T.R. \& Rahill A.A. (2000). A review of expressed emotion research in health care. Clinical Psychology Review 20, 633-666.

Weiner B. (1980). A cognitive (attribution) - emotion action model of motivated behavior: an analysis of judgements of help-giving. Journal of Personality and Social Psychology 39, 186-200.

WFSAD Newsletter (2002). Stigma-Sony Play Station characters explicitly labelled as mentally ill. Newsletter of the World Fellowship for Schizophrenia and Allied Disorders, Forth Quarter, p. 7.

Zimbardo P.G., Maslach C. \& Haney C. (2000). Reflections on the Stamford Prison Experiment: genesis, transformation, consequences. In Obedience to Authority: Current Perspectives on the Milgram Paradigm (ed. T. Blass), pp. 193-237. Eribaum: Mahwah, N.J 